\title{
A Novel Structural Analysis Program by Stiffness Method for Analysis of Trusses
}

\author{
Azhar Uddin ${ }^{1}$, Sumit Pahwa ${ }^{2}$ \\ ${ }^{1}$ M. Tech Scholar, CE Department, AIT, Ujjain, India \\ ${ }^{2}$ H.O.D, CE Department, AIT, Ujjain, India
}

\begin{abstract}
Structural analysis is the backbone of any engineering design by letting one knows ahead of time the behavior of any engineering structure under different loading conditions to which structure will come across throughout its life. This report demonstrates how a structure could be defined and analyzed using the program named structural analysis by stiffness method (SABSM).Moreover how a user can use this program as a learning tool for direct stiffness method specifically by going through each step of the solution reported back by the SABSM. SABSM is developed for static elastic structural analysis of $2 D$ and $3 D$ pin and rigid jointed frames and a learning tool for direct stiffness method. Structure could have any geometry and different end conditions.
\end{abstract}

Keywords: SABSM, FEM, Trusses, graphical user interface

\section{Introduction}

For analysis of any structure, it is modeled as a set of simple, idealized elements connected at nodes. Analysis by direct stiffness method can be divided into following steps

1) Formulation of element stiffness matrix in local Coordinates (K_e ).

2) Formation of element transformation matrix $T$.

3) Transformation of element stiffness matrix in global Coordinates (K_e).

4) Addition of all element stiffness matrices at pertinent DOF to form a structural stiffness matrix (K).

5) Formation of Nodal load vector (P) in global coordinates.

6) Formation of Element load Vector $\left(\boldsymbol{P}_{\boldsymbol{o e}}\right)$ in local coordinates for frames only.

7) Transformation of Element load vector in global coordinates for frames only.

8) Formation of Nodal displacement vector (U).

9) Solving to get unknown displacements at unconstrained joints.

10) Making use of displacements for step 6 to get reactions at constrained joints.

11) Transformation of global displacements to local displacements to calculate the member forces.

\section{Proposed System}

Several structural analysis program has been in existence, but from the point of view of simplicity and affordability there doesn't exist a single program which could be called as direct program which doesn't require any learning from the user point of view. Moreover the literature review suggests the use of several proprietary software for finite element analysis, but we think for analysis of simple structure such as trusses finite element method is not only extravagant but non-essentialalso. Thus keeping this in mind we have proposed a novel and simple structural analysis software that could and will help the research as well as academic fraternity.
We have built a graphical user interface in mat lab with the following capabilities:-

1. The GUI thus built will enable the user to create custom truss structure.

2. The truss thus created can have a single or varying parameters such as cross sectional area, elasticity coefficient etc.

3. The GUI will then give the solution to truss equations in both graphical as well as analytical form.

4. The GUI will also give a simulation of the displacement caused to the structure by loads.

5. The GUI will have the feature by which the structure could be saved and used for later use.

6. The GUI thus built will also enable the user to export the data into an excel file.

\section{Analysis of Property and Member Variations}

\subsection{Thickness}

Variability of thickness affects the strength of a member as it directly changes the cross sectional area available to resist internal forces due to loading. For this project, it was assumed that each member had a uniform thickness along its length for each of the four sides, but that the value of thickness relative to the nominal was random. The variability of thickness in HSS members was obtained through recently collected data for a report to AISC which characterized dimensional variability in HSS members produced in the US (Christopher M. Foley, personal communication, February 7, 2011). This report contains data on the variation of several dimensional measurements, however only thickness data was utilized in this project. Samples were obtained from three HSS manufactures in the US for 6 typical cross sections, ranging in size from 12 " $\times 6$ " to 3 " 33 " and thicknesses from $5 / 8$ " to $3 / 16$ ". There were a total of 28 samples measured and sample lengths ranged from 11 to 13 inches. Thickness measurements were taken at 16 locations around the cross section: 3 along each face and 1 at each corner at $1 \mathrm{inch}$ from both ends of each specimen. 


\section{International Journal of Science and Research (IJSR) \\ ISSN (Online): 2319-7064}

Index Copernicus Value (2013): 6.14 | Impact Factor (2014): 5.611

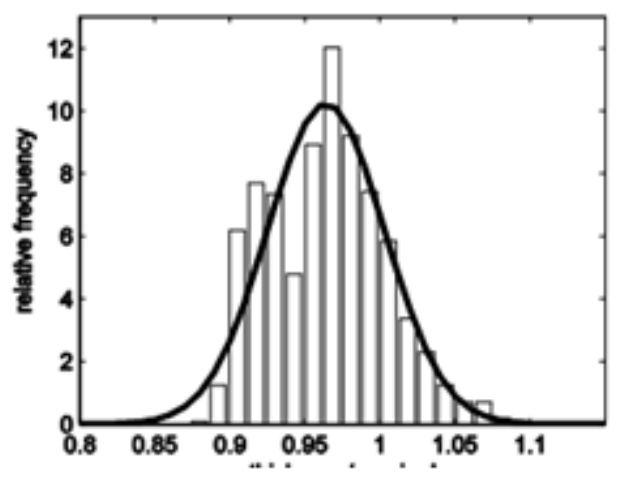

Figure 3.1: Histogram and normal PDF fit of HSS wall thickness

\subsection{Analysis of Young's Modulus and Yield Stress}

Material properties such as Young's modulus, E, and yield stress, FY, affect the strength of structural members by varying at which stress they begin to experience plastic deformations and at which strain this occurs

\subsection{Implementation in Models}

Latin hypercube sampling was employed to reproduce values of thickness, Young's modulus, and yield stress for chord and web members for all simulations. In the 2D models, all chord members were correlated, and all web members were correlated. This reflects how chord members and web members come from the same batch and have similar properties. Additionally, if all $\mathrm{n}$ members were uncorrelated, the variability would be much smaller than a single member's variability as shown below (Eq. 3.1) where $\mathrm{V}$ is the coefficient of variation.

$$
V_{\text {system }}=\frac{V_{\text {member }}}{\sqrt{n}}
$$

In the 3D models, all chord members in a truss were correlated and all web members in a truss were correlated, however the members were not correlated between trusses. Thus the 3D model was a system of independent trusses, and system behavior was observed through the simulations of systems of independent trusses.

\section{Analysis of Plane Truss Structure}

The proposed truss structure is $72 \mathrm{ft}$. with $18 \mathrm{ft}$. height. The proposed truss structure is composed of two materials: steel and aluminum. The modulus of elasticity of steel is $29,000 \mathrm{ksi}$ and the modulus of elasticity of aluminum is $10,000 \mathrm{ksi}$. The structural configuration of proposed structure can be seen in Figure 2. Figure 3 shows the analytical model ofplane truss structure. The main data input to the MATLAB program are joint data, support data, material property data, cross-sectional property data, member data and load data. Joint data of the proposed plane truss consists of the total number of joints, $\mathrm{NJ}$, and the global coordinates of each joint. There are six joints in the proposed truss. The position ofeach joint is specified by means of the global coordinates of the joint. Joint coordinates are stored in a joint coordinate matrix, COORD of order $\mathrm{NJ} \times 2$. Support data are stored in the form of a matrix MSUP of order NS $\times(\mathrm{NCJT}+1)$ and this matrix is called a support data matrix. In the proposed plane truss, the number of joints that are attached to supports, NS, is three. For a plane truss, the number of degree of freedom of a free joint, NCJT, is two. The joint numbers and their corresponding directions of restraints are defined in the support data matrix. The directions of restraints of each support joint are specified by using two-digit code, 0 or 1 . If the joint is free to translate, it is defined as 0 and if the joint is restrained, 1 is selected. Material property data are defined by storing modulus of elasticity of each arterial used in the structure ina elastic modulus vector, EM. The number of rows of EM is equal to the number of materials used in the plane truss, NMP. In this proposed truss structure, two materials; namely, steel and aluminum are used and so NMP is two. The steel is arbitrarily assigned to be material number 1 and the aluminum is arbitrarily assigned to be material number 2 . In cross-sectional property data, the cross-sectional areas are stored in a cross-sectional property vector, $\mathrm{CP}$. The number of rows of $\mathrm{CP}$ is equal to the number of different cross-section types used for the truss members, NCP. There are three different cross-section types in this proposed truss soNCP is three.

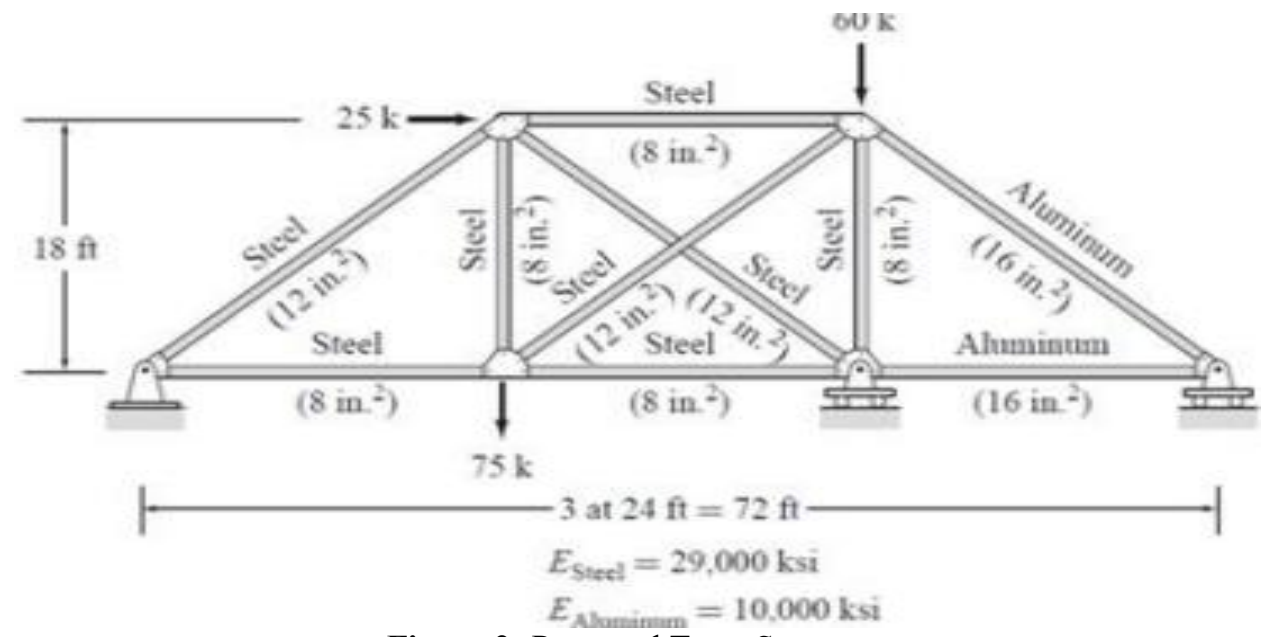

Figure 2: Proposed Truss Structure 


\section{International Journal of Science and Research (IJSR)

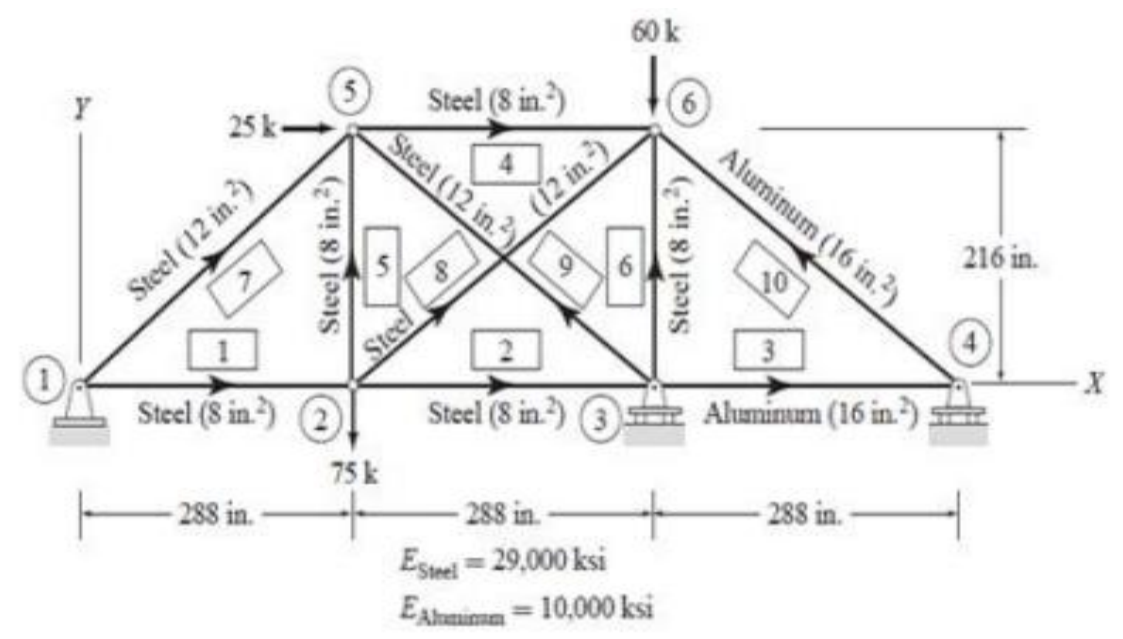

Figure 3: Analytical Model of Proposed Truss structure

The cross-sectional areas of three types are 8 in.2, 12 in.2and 16 in. 2 respectively. The numbers 1,2 and 3 are selected as the cross-section type number for each area. Member data includes the total number of members of the truss, NM, and the beginning joint number, the end joint number, the material number and the cross-section type number for each member. Since the proposed truss has ten members, NM is ten. These member data are stored in the form of a member data matrix, MPRP of order NM $\times 4$. Load data contains the number of joints that are subjected to external loads, NJL, and their joint numbers and the magnitudes of the force components in the $\mathrm{X}$ and $\mathrm{Y}$ directions. The numbers of the loaded joints are stored in an integer vector, JP. The number of rows of JP is equal to NJL. As the proposed truss has three joints that are subjected to external loads of $75 \mathrm{k}, 25 \mathrm{k}$ and $60 \mathrm{k}, \mathrm{NJL}$ is three. The magnitudes of forces and the corresponding load components in the $\mathrm{X}$ and $\mathrm{Y}$ directions are stored in a load data matrix, PJ of order NJL $\times$ NCJT.

\section{Analysis of Determinate Trusses}

The trusses are classified as determinate and indeterminate. They are also classified as simple, compound and complex trusses. We have plane and space trusses. The joints of the trusses are idealized for the purpose of analysis. In case of plane trusses the joints are assumed to be hinged or pin connected. In case of space trusses ball and socket joint is assumed which is called universal joint. If members are connected to a hinge in a plane or universal joint in space, the system is equivalent to $\mathrm{m}$ members rigidly connected at the node with hinges or socketed balls in $(\mathrm{m}-1)$ number of members at the nodes as shown in figure 6.1. In other words it can be said that the members are allowed to rotate freely at the nodes. The degree of freedom at node is 2 for plane truss (linear displacements in $\mathrm{x}$ and $\mathrm{y}$ directions) and 3 for space truss (linear displacements in $\mathrm{x}, \mathrm{y}$ and $\mathrm{z}$ directions). The plane truss requires supports equivalent of three reactions and determinate space truss requires supports equivalent of six reactions in such a manner that supporting system is stable and should not turn into a mechanism. For this it is essential that reactions should not be concurrent and parallel so that system will not rotate and move. As regards loads they are assumed to act on the joints or points of concurrency of members. If load is acting on member it is replaced with equivalent loads applied to joints to which it is connected. Here the member discharges two functions that is function of direct force member in truss and flexural member to transmit its load to joints. For this member the two effects are combined to obtain final internal stress resultants in this member.

The truss is said to be just rigid or determinate if removal of any one member destroys its rigidity and turns it into a mechanism. It is said to be over rigid or indeterminate if removal of member does not destroy its rigidity.
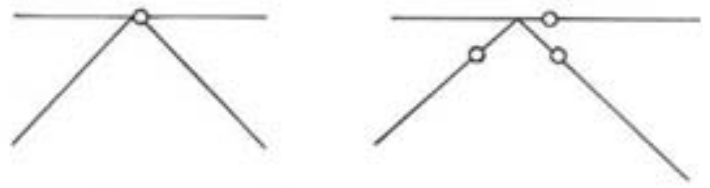

Figure 6.1: hinged joint of truss

\subsection{Plane truss}

The stable and just rigid or determinate smallest plane truss as shown in Fig.9.3. Comprises of a triangle with three nodes and three members. Two members and a pin joint are added to expand the truss. Total number of non-parallel and non-concurrent links or reactive forces required tosupport $j$ number of joints is 3 . Total number of unknowns is number of member forcesand reactions at the supports. Number of available equations is $2 \mathrm{j}$. Therefore for determinate plane truss system:

$$
\begin{aligned}
& (m+3)=2 j \\
& m=(2 j-3)
\end{aligned}
$$

Hinge support is equivalent of two reactions or links and roller support is equivalent of one reaction or link.

\section{Results and Simulation}




\section{International Journal of Science and Research (IJSR) \\ ISSN (Online): 2319-7064}

Index Copernicus Value (2013): 6.14 | Impact Factor (2014): 5.611

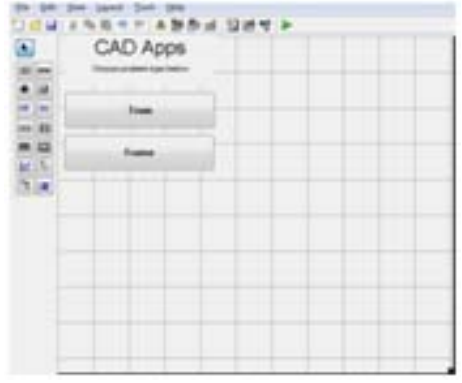

Figure 5.1: basic GUI of the Project

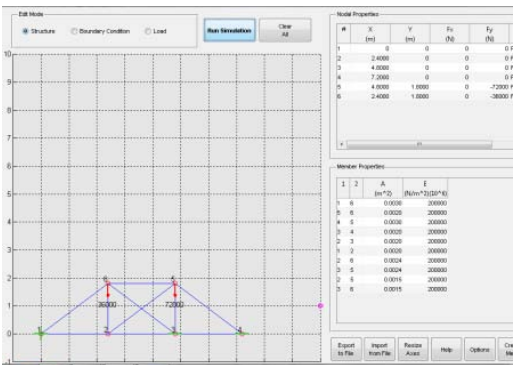

Figure 5.2: Model built using our program

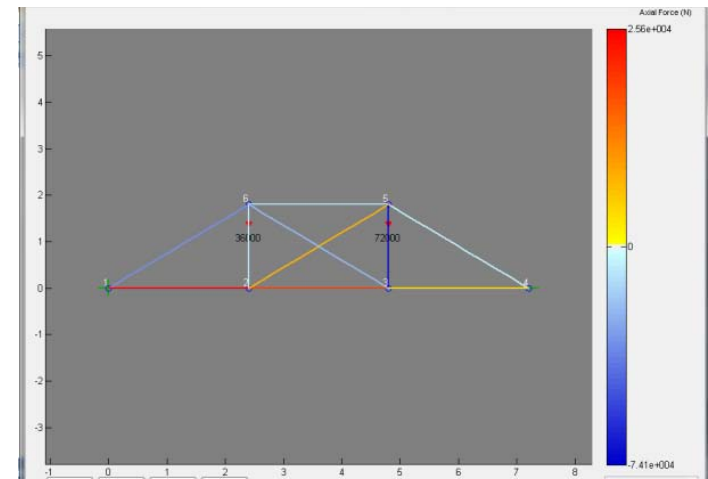

Figure 5.3: After Simulation of the code

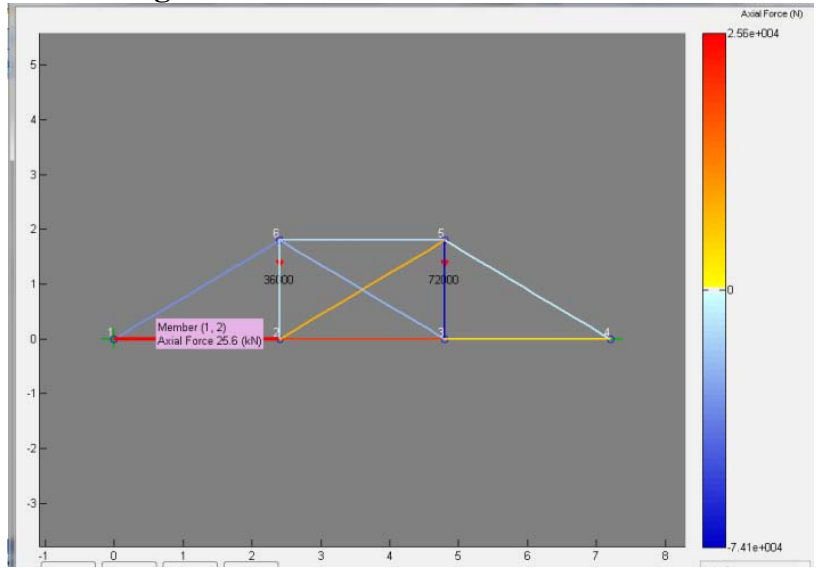

Figure 5.4: Showing one of the Axial Forces

Figure 5.4Showing one of the Axial Forces Beetween Node1 and Node 2 is $25.6 \mathrm{kN}$.

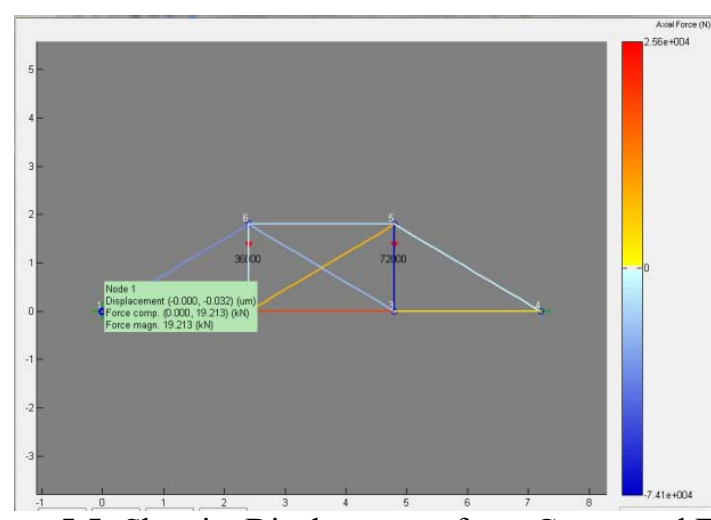

Figure 5.5: ShowingDisplacement, force Comp. and Force magn.

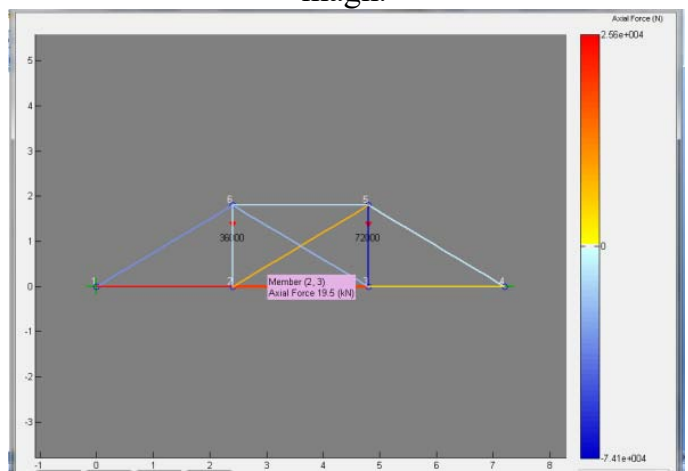

Figure 5.6: Showing the Axial Force

Figure 5.6Showing the Axial Force Beetween Node2 and Node 3 is $19.5 \mathrm{kN}$.

\section{Conclusion}

Nowadays computer aided simulation are a part and parcel of almost any engineering discipline. The need for a simple, clear and resourceful application that could help in the analysis of two dimensional trusses was highly required.

Thus to complete this task this project was undertaken. Although not the most professionally built program but this program was developed aiming at the undergraduate students which can use this program easily and effectively for learning purpose. The features added to the program help the user to export and import data from other programs as well.

As an application of these fundamentals, the truss project tasks students with analyzing and building a 2-dimensional truss using mat board (used in picture framing) and common manila folders. One of the unique features of the trusses used in this project is the use of pinned joints. Typically, truss projects use glue or other methods of assembling the joints. Part of the error between calculated results and actual performance of the trusses is a result of this mounting. Methods for analyzing trusses are based upon true pinned joints.

\section{References}

[1] ABAQUS, ABAQUS/Standard Version 6.7-1, D Systems, Editor 2007.

[2] American Institute of Steel Construction (AISC), (1986). Load and Resistance Factor Design Manual of 


\section{International Journal of Science and Research (IJSR) \\ ISSN (Online): 2319-7064}

Index Copernicus Value (2013): 6.14 | Impact Factor (2014): 5.611

Steel

Construction, 1st ed., Chicago. American Institute of Steel Construction (AISC), (2000). Load and Resistance Factor Design Specification for Steel Hollow Structural Sections, Chicago.

[3] American Institute of Steel Construction (AISC), (2005). Steel Construction Manual, $13^{\text {th }}$ ed., Chicago.

[4] Association of Steel Construction on Milan, (1966). "Test Certificate for Column Buckling, Short Column Tests, and Traction Tests." Institute of Constructional Science, Milan University of Technology (Politecnico), Milan.

[5] Blum, Hannah B. (2012). "Framework for determining system resistance factors in LRFD using advanced second order analysis for HSS truss systems." Master's Thesis, Johns Hopkins University, Baltimore,Maryland, USA. 440.

[6] Buonopane, Stephen G. (2008). "Strength and Reliability of Steel Frames with Random Properties." Journal of Structural Engineering, 134(2), 337-344.

[7] Buonopane, S. G. and Schafer, B. W. (2006). "Reliability of Steel Frames Designed with Advanced Analysis."Journal of Structural Engineering, 132(2), 267-76.

[8] Coutie, et. al. (1987). "Testing of full scale lattice girders fabricated with RHS members", University of Nottingham. In Structural Assessment - the use of full and large scale testing, pages 98-105. Edited byGaraset. al., London, UK.

[9] Clarke, M. J. et al., (1992). "Advanced Analysis of Steel Building Frames." Journal of Constructional Steel Research, 23, 1-29.

[10] Cran, J. A., (1989). "The Engineer's Guide to Hollow Sections." Proc., Canadian Society for Civil Engineering Annual Conference, St. John's, Newfoundland.

[11] Davison, T. A. and Birkemoe, P. C. (1982). "Column behavior of cold-formed hollow structural steel shapes."Canadian Journal of Civil Engineering, 10, 125-141.

[12] De Koning, C. H. M., and Wardenier, J., (1979). Tests on Welded Joints in Complete Girders Made of Square Hollow Sections, Stevin Laboratory, Department of Civil Engineering, Delft University of Technology, Delft, The Neatherlands.

[13] umonteil, Pierre, (1989). "In-Plane Buckling of Trusses.” Canadian Journal of Civil Engineering, 16, 504-518.

[14]Ellingwood, Bruce R., (2000). "LRFD: implementing structural reliability in professional practice." Engineering

Structures, 22, 106-115.Ellingwood, Bruce et al., (1980).

[15] Development of a Probability Based Load Criterion for American National

Standard A58, Building Code Requirements for Minimum Design Load in Buildings and Other Structures, U.S.Department of Commerce / National Bureau of Standards, Gaithersburg, MD.Ellingwood, Bruce and Galambos, Theodore ., (1982).

[16]"Probability-Based Criteria for Structural Design."Structural Safety, 1, 15-26. Ellingwood, Bruce and O'Rourke, Michael, (1985). "Probabilistic Models of Snow Loads on Structures."Structural Safety, 2, 291299.

[17]Ellingwood, Bruce and Redfield, Robert, (1983). "Ground Snow Loads for Structural Design." Journal ofStructural Engineering, 109, 950-964.

[18] Moen, Christopher D., et al. (2008). "Prediction of residual stresses and strains in cold-formed steel members." Thin-Walled Structures, 46, 1274-1289.

[19] Nowak, Andrzej S. and Collins, Kevin R., (2000). Reliability of Structures, The McGraw Hill Companies, Inc.,

[20]New York.Packer, Jeffery A., (1986). "Design Examples for HSS Truss." Canadian Journal of Civil Engineering, 13, 460-473.

[21] Packer, J. A., and Davis, G., (1989). "On the Use and Calibration of Design Standards for SHS Joints." The Structural Engineer, 67(21), 377-386.

[22] Packer, Jeffery A., (1993). "Moment Connections between Rectangular Hollow Sections." Journal of Constructional Steel Research, 25, 63-81 